Article

\title{
Evaluation of the Mechanical Instability of Mining Roadway Overburden: Research and Applications
}

\author{
Housheng Jia ${ }^{1,2, *}$, Kun Pan ${ }^{1, *}$, Shaowei Liu ${ }^{1,2}$, Bo Peng ${ }^{3}$ and Kai Fan 4 \\ 1 School of Energy Science and Engineering, Henan Polytechnic University, Jiaozuo 454003, China; \\ 1swxll@126.com \\ 2 Collaborative Innovation Center of Coal Work Safety, Henan Province, Jiaozuo 454000, China \\ 3 Technology Center of Sichuan Province Coal Industry Group, Chengdu 610000, China; pb2007@126.com \\ 4 Sichuan Huayingshan Longtan Coal and Electricity Co., LTD, Guangan 638020, China; \\ support_2013@126.com \\ * Correspondence: jiahousheng@126.com (H.J.); 211802020017@home.hpu.edu.cn (K.P.)
}

Received: 16 September 2019; Accepted: 5 November 2019; Published: 8 November 2019

\begin{abstract}
Under the superposed action of the primary rock stress and the mining stress, the compound roof of a roadway will have irregular plastic failure zone with greater depth, resulting in a wide range of non-uniform deformations and roof failures. Mastering the deformation and failure characteristics of this roof is essentially to recognize the development of the plastic zone of a compound roof. In this paper, the on-site roof detection method is mainly adopted to arrange a large number of boreholes for visualization and the deep displacement monitoring with the high-density points. Combined with numerical simulations, the rupture development characteristics and deformation mechanisms of the compound roof are revealed. The results show that the magnitude and direction of the principal stress of surrounding rock in a mining roadway are constantly changing, and the penetrating phenomenon will occur during the plastic zone expansion process. The order of the compound roof rupture as follows: shallow strata plastic failure, deep strata penetrating plastic failure and middle strata rupture. Severe roof deformation is mainly caused by plastic failure, and the strong deformation pressure caused by deep strata penetration plastic failure can easily lead to tensile failure and rupture in the middle strata. According to the plastic zone penetration development of the compound roof, the hierarchical support design led by the long-extension bolt is carried out on the test roadway. The monitoring results show that the roof is controlled well. The research results can provide a reference for the control of compound roofs in mining roadways.
\end{abstract}

Keywords: mining roadway; compound roof; plastic failure; roof fall

\section{Introduction}

The plastic failure of roadway roofs is an important reason for the overall rupture of the roofs, the large deformation of the surrounding rock, and the failure of supports which can lead to roof collapse. The support design is usually based on the geometry of the plastic zone of the surrounding rock [1-4]. It is found that the roadway-surrounding rock is in a highly deviated stress environment because of the influence of mining and the surrounding rock plastic zone will have a dangerous expansion, roof stability is seriously affected, the plastic zone's shape is no longer a circular, elliptical and other regular shape as in traditional theory [5-8]. However, the roadway-surrounding rock is generally heterogeneous and has layered-compound roof characteristics $[9,10]$. Revealing the development of the plastic zone in the compound roof during the mining process has practical significance for design of the roof support parameters, the choice of supporting time and the identification of hidden roof fall dangers. 
Scholars at home and abroad have conducted a lot of research on the distribution of plastic zones and roof failures in mining roadways with compound roofs. Many scholars start from the stress environment around the surrounding rock of mining roadway to analyze the surrounding rock failure characteristics under the action of this stress environment. Dolezalova et al. [11-17] used FLAC3D, FDEM, and 3EDC to simulate the stress distribution and failure development of deep engineering, they clarified that the development of stress environment is the essential cause of the deformation and destruction of surrounding rock. Chang et al. [18-20] revealed the surrounding rock stability control mechanism of deep rock roadway by analyzing the stress development characteristics, deformation and failure mechanisms of surrounding rock after excavation of deep rock roadway. Gao et al. [21] adopted the UDEC Trigon approach to investigate the mechanisms of roadway squeezing, and the model captures the roadway extrusion process under severe mining-induced stresses. Ma et al. [22] introduced the case study under the conditions of medium-thick coal seam and compound roof, and studied the behavior mechanism of the strata through theoretical analysis. Yuan et al. [23-26] deduced the boundary equations for the plastic zone around the deep roadway, and discussed the development of the plastic zone. It is found that the influence of mining on the plastic zone is more sensitive than that on the shallow one.

Many scholars have proposed a targeted roof control technology and disaster warning method by analyzing the failure mechanisms of mining roadway roof. He et al. [27-29] used the material point method (MPM) to simulate the large deformation and failure process of deep rocks, and proposed the support idea of large deformation roadway under the influence of mining. Gu et al. [30,31] measured the failure characteristics of the surrounding rocks on the mining roadway roof by using a strata detector, and investigated the occurrence mechanism of roof-fall and the related supporting control method in detail. Xie et al. [32] used discrete element numerical simulation to analyze the separation characteristics of compound roof in mining roadway, and established the gray algebraic curve model (GAM) to predict the roof fall accidents. Although the deformation and instability of mining roadways have been studied, our understanding of the failure mechanism is still far from being complete and satisfactory. The morphological characteristics and development process of the plastic zone are not clear in mining roadways with compound roofs.

This research takes the asymmetric large deformation mining roadway of the Baode coal mine in China as the background. Combined with the previous research results, the paper systematically studies the development of the plastic zone through the field measurement, numerical simulation and theoretical analysis. At the same time, according to the development of the plastic zone, the hierarchical support design of long-extension bolt support is carried out. The research results provide reference for the roof fall control and support parameter design of compound roof in mining roadway.

\section{General Situation of Roadway Engineering}

The Baode coal mine of the Shenhua Shendong Coal Group Co., Ltd. is located in Baode County, Shanxi Province, China, as shown in Figure 1. The main mining area of Baode Coal Mine is the 8\# coal seam with a depth of about $400 \mathrm{~m}$. Its coal seam thickness is $3.7-9.2 \mathrm{~m}$ and dip angle is $3^{\circ}-7^{\circ}$. There is top coal with a certain thickness on the roof of mining roadway. In terms of the roof lithology, the top of the roof includes coal, thin mudstone (thickness is only $0.2 \mathrm{~m}$ ), sandy mudstone and coarse sandstone from shallow to deep. The rock pillar diagram is shown in Figure 2. The layout of the Baode coal mine mining roadway is a "three-roadway arrangement". They are No.1 return airway, namely a gas drainage roadway, No.2 return airway and the main haulage gateway, No.1 coal pillar is $12 \mathrm{~m}$ and No. 2 coal pillar is $25 \mathrm{~m}$. Both return airways are affected by the mining influence of the coal face and the adjacent coal face, as shown in Figure 3. When it comes the on-site coal face mining, the ground pressure behavior of the roadway about $300 \mathrm{~m}$ behind the coal face is extremely severe, with obvious asymmetric deformation, support failure and other phenomena, as well as many roof fall and roof leakage accident incidents. The failure development of the surrounding rock in the roadway under the 
compound roof conditions is studied, which plays a significant role in the scientific design of the roof support parameters and the safety during the roadway service period.

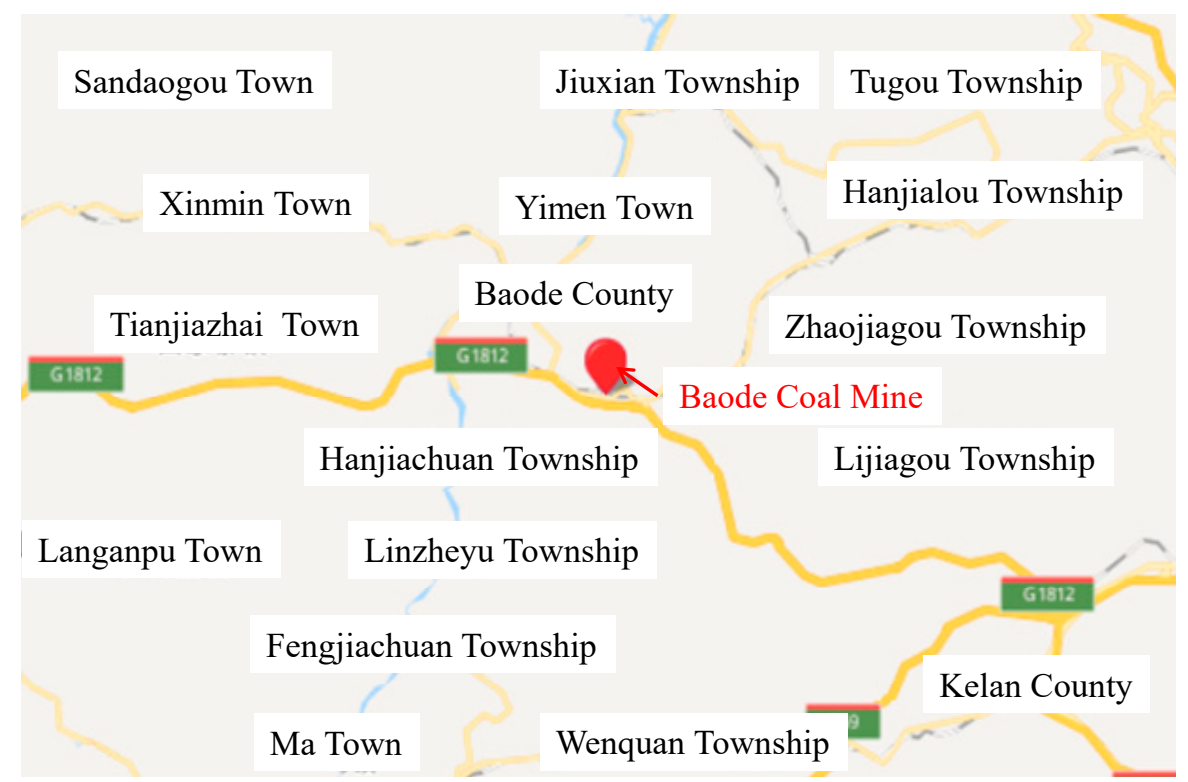

Figure 1. The location of the Baode coal mine.

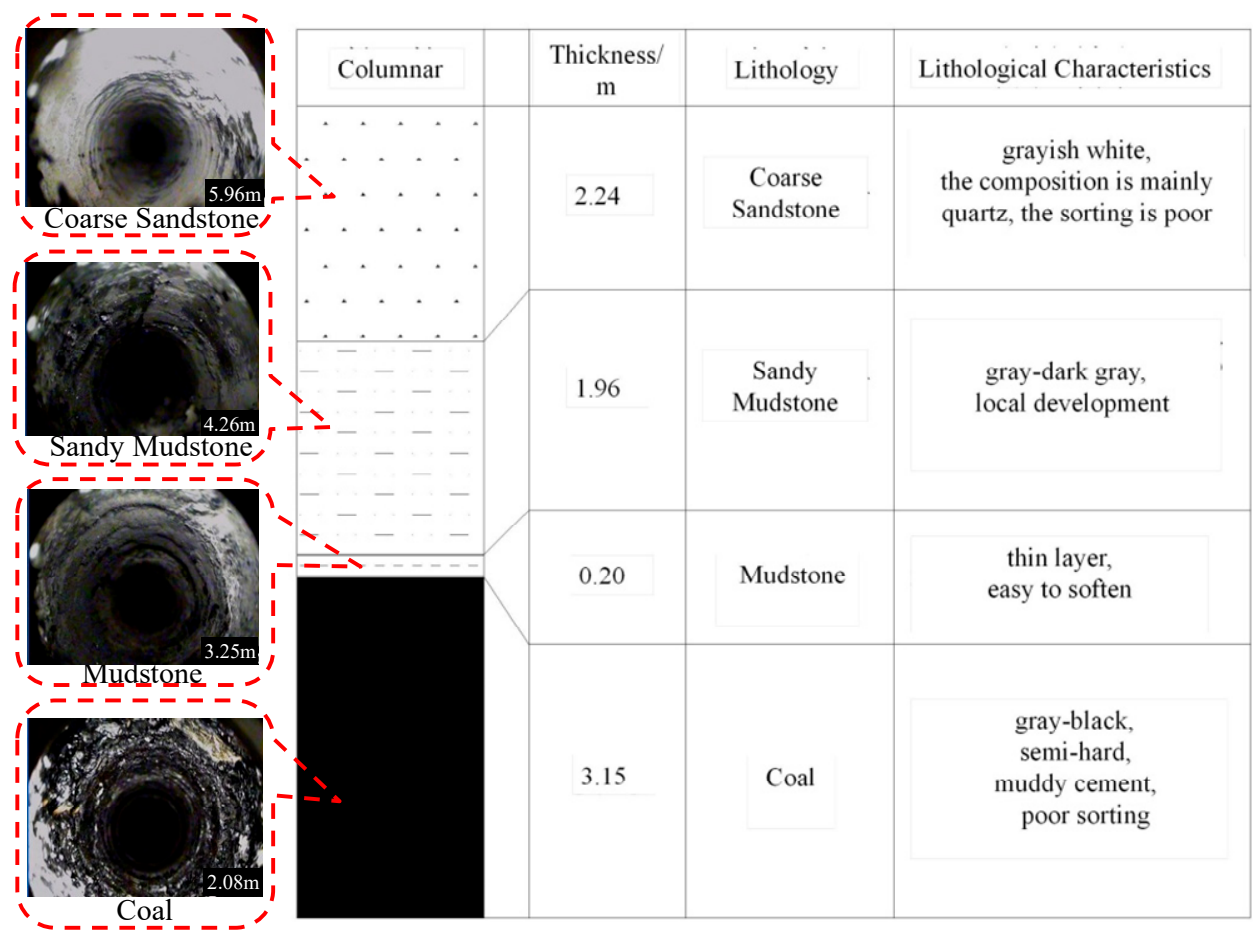

Figure 2. Roof strata structure of the panel 81305 No.2 return airway. 


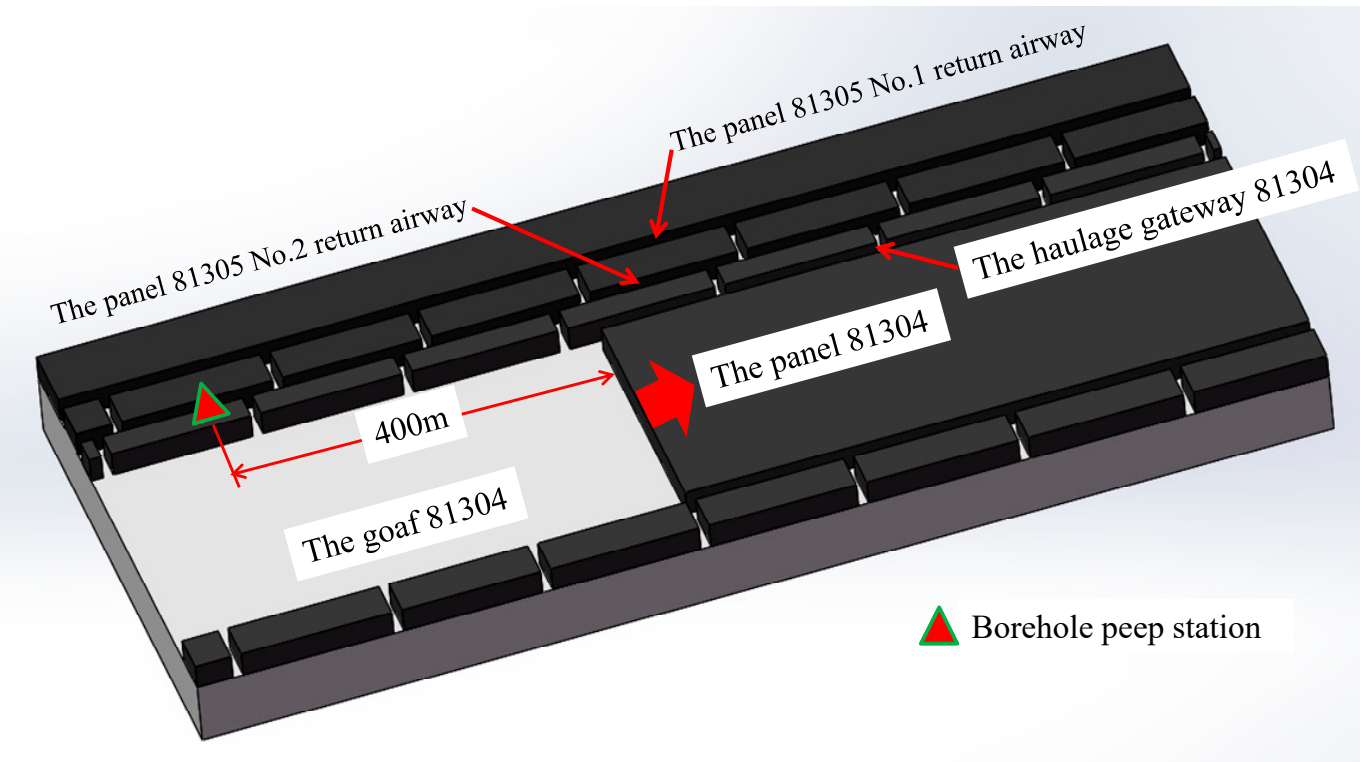

Figure 3. Three-roadway arrangement in the panel of Baode coal mine.

\section{Roof Rupture Form and Plastic Zone Development of Roadway}

\subsection{Rupture Characteristics of Roadway Roof before Mining}

The roof is always stable after the two return airways are formed and before the influence of mining. The roadway support parameters adopted can meet the support requirements well, and the roof subsidence is not too large, which generally does not exceed $70 \mathrm{~mm}$ and there is no support failure phenomenon. Figure 4a shows the photos before the mining influence of the panel 81304 No.2 return airway.

While peeping into the roof strata structure of No.2 return airway near the panel 81305, the roof rupture situation is analyzed after excavation of this roadway. As shown in Figure $4 \mathrm{~b}$, within the scope of the peeping depth of $8.0 \mathrm{~m}$, only the shallow area of $0.3 \mathrm{~m}$ has the rupture, and other areas are relatively complete.

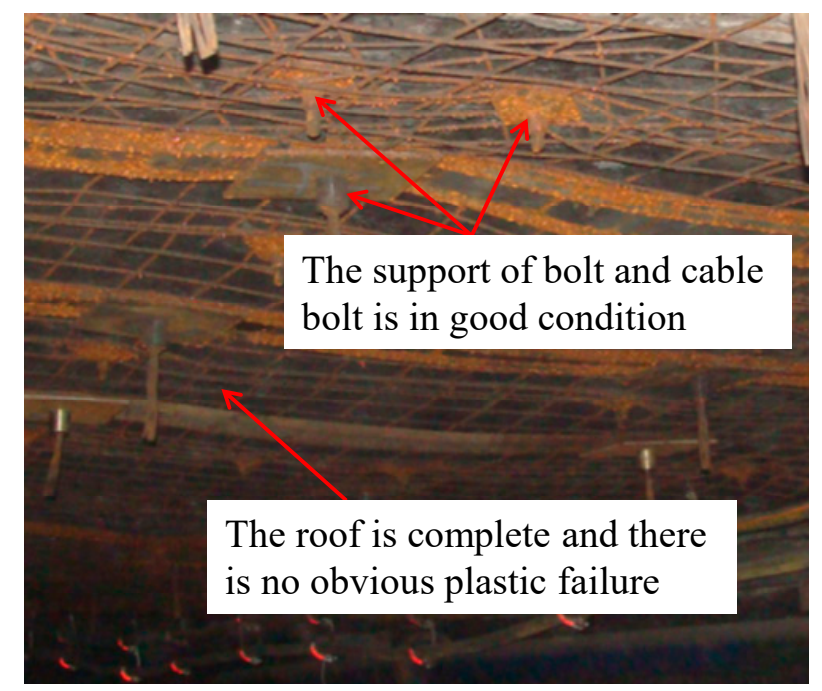

(a) The photo before the mining influence of the panel 81304 No.2 return airway.

Figure 4. Cont. 


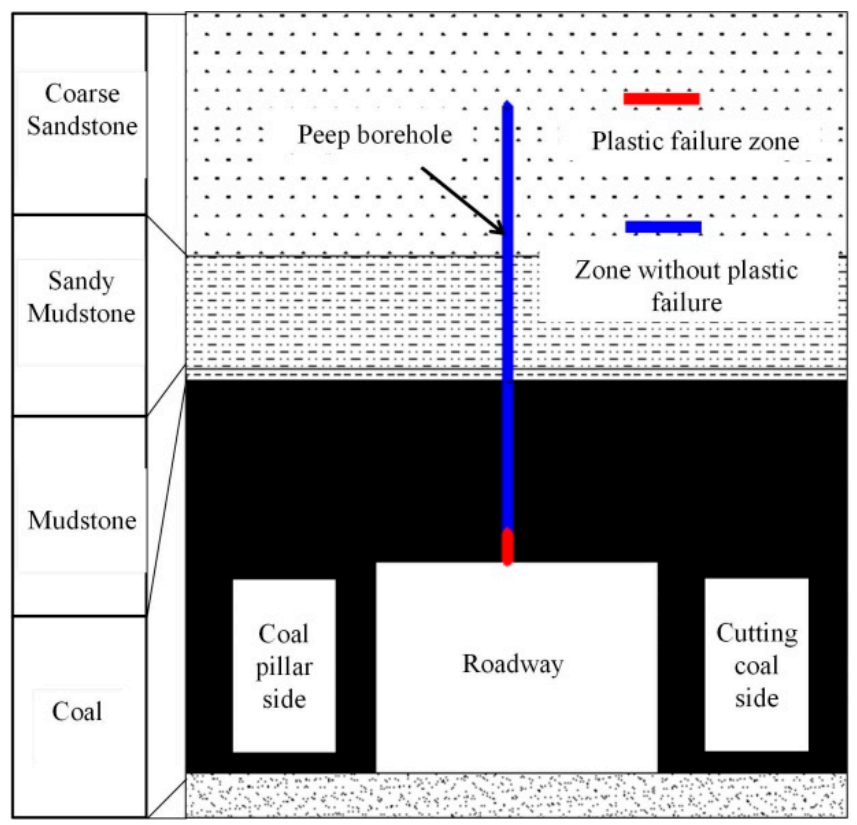

(b) Analysis of the roof rupture situation after excavation of the roadway.

Figure 4. Roof rupture of the roadway before mining.

\subsection{Distribution of Plastic Zone in Roadway after Mining}

The plastic deformation zone of the roof of the panel 81305 No.2 return airway in the Baode coal mine was analyzed using numerical simulations and field measurements. Firstly, in order to discuss the changes of the two principal stresses $\left(\sigma_{1}\right.$ and $\left.\sigma_{3}\right)$ at a fixed point of the roadway on both sides of the coal face after mining, a larger-scale numerical model is established to simulate the stress environment around the panel. As shown in Figure 5a, the model's height is $300 \mathrm{~m}$ and the length is $550 \mathrm{~m}$. At the same time, the grid at the location of the mining roadway is carefully divided. The grid's width of this area is $1.0 \mathrm{~m}$. Table 1 shows the rock mechanics parameters of the coal seam and the roof and floor used by numerical simulation. Applying a vertical stress on the upper boundary of the model, which is equal to the weight of the rock above it, about $12 \mathrm{MPa}$, and the lateral pressure coefficient is 1.2. The initial stress state is: the $\mathrm{Z}$ direction is loaded with $12.0 \mathrm{MPa}$, and the $\mathrm{X}$ and $\mathrm{Y}$ directions are loaded with $14.4 \mathrm{MPa}$. The initial stress is assumed to be uniform because the actual depth of the coal seam changes little. In the horizontal direction of the model, the displacement and initial velocity in the $x$ direction are limited. And the displacement and initial velocity in the directions of $x, y$, and $z$ are limited at the bottom of the model.The Mohr-Coulomb criterion based on the elastic-plastic theory is used for the simulation.

After the excavation of the coal face, the stress around the coal face is redistributed. Figure $5 \mathrm{~b}$ shows the distribution of the principal stress in the side of the goaf at the position of $300 \mathrm{~m}$ behind the panel. It shows the stress concentration occurs within the range of 5-18 $\mathrm{m}$ on the side of the goaf. The maximum principal stress reaches $42-45 \mathrm{MPa}$, which is about four times of the primary rock stress. It has exceeded the uniaxial compressive strength of the surrounding rock of the roadway. Figure $5 \mathrm{c}$ shows the numerical simulation results of the ratio of the maximum principal stress to the minimum principal stress on the side of the goaf. It can be seen that the farther away it is from the goaf, the more obvious is the gradient of the principal stress ratio decreases. In the range of $18-50 \mathrm{~m}$ from the goaf, the principal stress ratio is $2-3$, while in the range of $18 \mathrm{~m}$ from the goaf, the principal stress ratio is $3-5$. Besides, as the distance from the edge of the goaf is different, the direction of principal stress is also changing. The closer it is from the edge of the goaf, the larger the deflection angle of the principal stress direction is. And the maximum principal stress is about $50^{\circ}$ to the side of the goaf compared to the primary rock stress at the position about $20 \mathrm{~m}$ from the edge of the goaf. The panel 81305 No. 2 
return airway shown in Figure 3 is in the high stress difference region of the deflection of the principal stress direction. The shape of the plastic zone in the turbulent superimposed stress field environment will exhibit the maximum depth toward the roof.

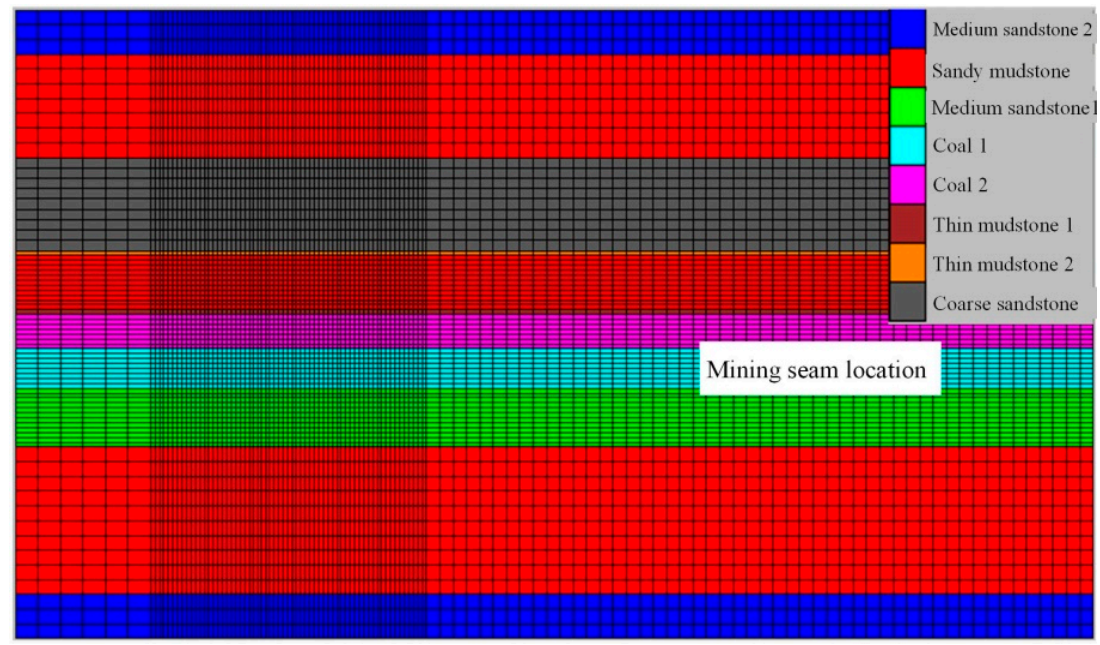

(a) Numerical model of the $8 \#$ coal seam roof and floor.

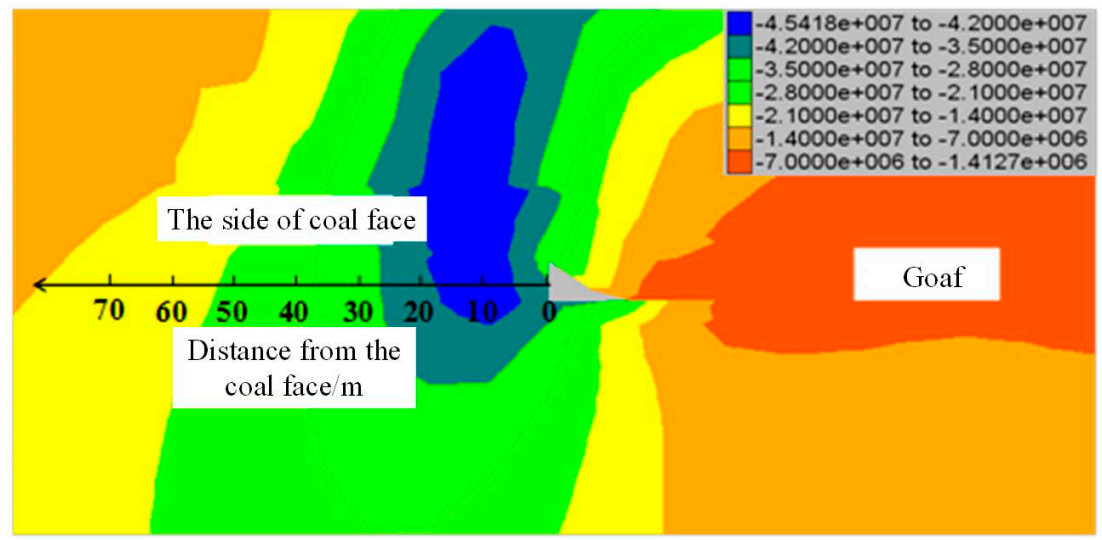

(b) Maximum principal stress cloud.

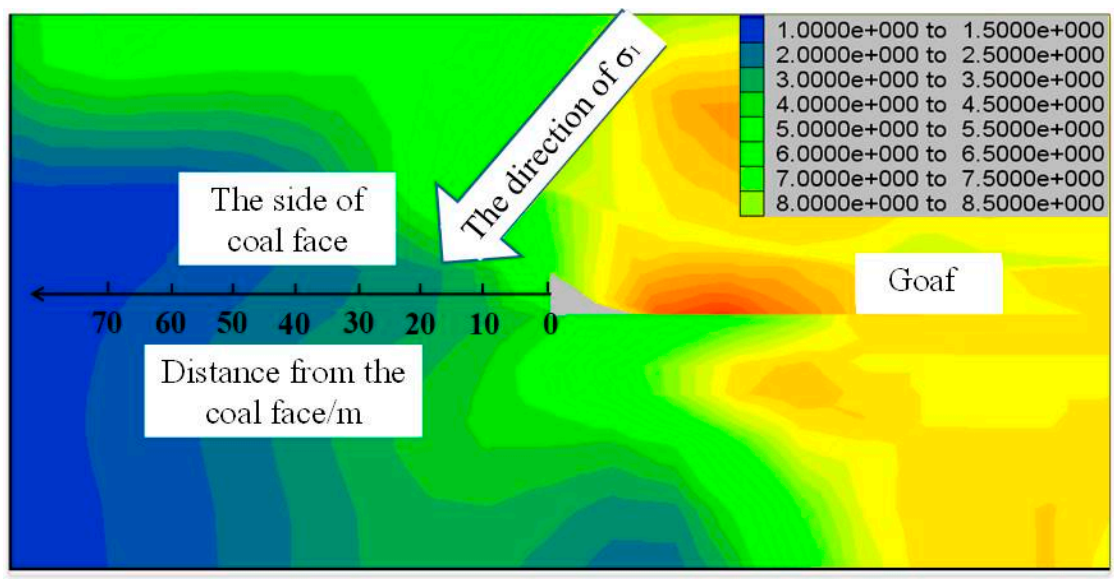

(c) Principal stress ratio $\left(\sigma_{1} / \sigma_{3}\right)$ distribution cloud.

Figure 5. Principle stresses distribution characteristics of goaf lateral side surrounding rock. 
Table 1. Rock mechanics parameters of the coal seam roof and floor.

\begin{tabular}{|c|c|c|c|c|c|c|}
\hline Layer Mark & $\begin{array}{c}\text { Friction/ } \\
\left({ }^{\circ}\right)\end{array}$ & $\begin{array}{c}\text { Cohesion/ } \\
\mathrm{MPa}\end{array}$ & $\begin{array}{l}\text { Density/ } \\
\left(\mathrm{kg} / \mathrm{m}^{3}\right)\end{array}$ & $\begin{array}{c}\text { Shear } \\
\text { Modulus/GPa }\end{array}$ & $\begin{array}{c}\text { Bulk } \\
\text { Modulus/GPa }\end{array}$ & $\begin{array}{c}\text { Tensile } \\
\text { Strength/MPa }\end{array}$ \\
\hline Coarse Sandstone & 28 & 7.0 & 2700 & 8.2 & 9.7 & 1.14 \\
\hline Sandy Mudstone & 23 & 2.6 & 2200 & 4.4 & 5.5 & 0.39 \\
\hline Thin Mudstone & 21 & 2.3 & 2600 & 5.1 & 2.6 & 0.38 \\
\hline Coal & 27 & 5.0 & 1400 & 5.5 & 6.7 & 0.58 \\
\hline Medium Sandstone & 28 & 6.0 & 2500 & 7.5 & 8.1 & 0.81 \\
\hline
\end{tabular}

The absolute value of the maximum principal stress at the center of the panel 81305 No. 2 return airway is about $35 \mathrm{MPa}$, and the ratio of the principal stress is about 3.0-3.5. The angle between the maximum principal stress and the vertical direction is about $46^{\circ}$. Under the stress condition, the angle between the normal direction of the rock and the vertical direction is $46^{\circ}$ to facilitate the loading of the principal stress, as shown in Figure 6a.

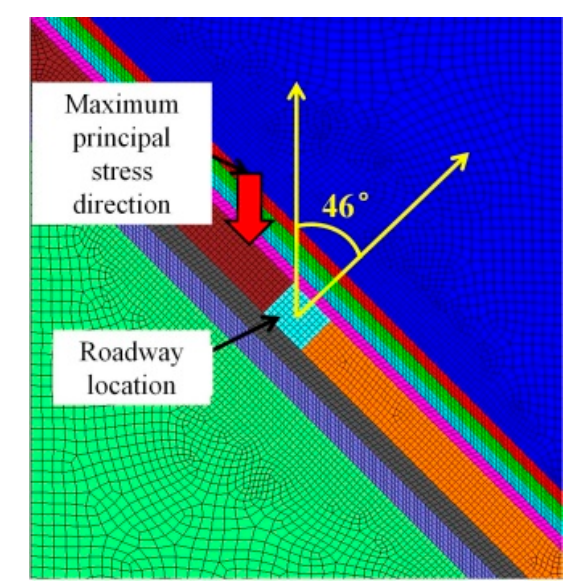

(a) Numerical model.

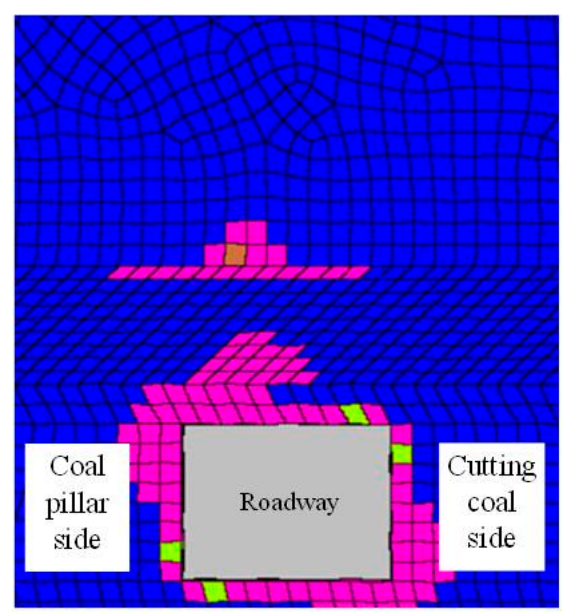

(b) Roof plastic zone simulation results.

Figure 6. Cont. 


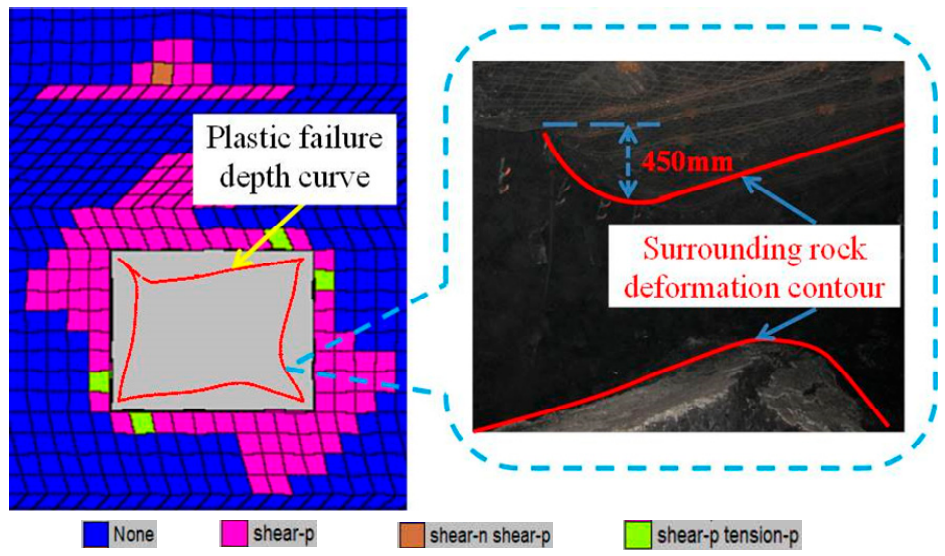

(c) Comparison of field photos and numerical simulation results.

Figure 6. Roof deformation and failure after mining of the panel 81305 No. 2 return airway.

Combined with the roof rock structure shown in Figure 2 is modeled by ANSYS software, then imported into the FLAC3D simulation software. In the horizontal direction of the model, the displacement and initial velocity in the $x$ direction are limited. And the displacement and initial velocity in the directions of $\mathrm{x}, \mathrm{y}$, and $\mathrm{z}$ are limited at the bottom of the model. The simulation adopts the Mohr-Coulomb criterion based on the elastic-plastic theory, the behaviour of the strata is perfectly plastic after calculation. The calculation is carried out through the process of loading, the assignment of mechanical parameters of each rockstrata, and the excavation of the roadway.

Figure $6 \mathrm{~b}$ shows the numerical simulation results of plastic zone distribution of the panel 81305 No.2 return airway in the Baode coal mine. It can be seen that the plastic zone distribution of this roadway presents the morphological characteristics of maximum failure depth toward the roof, and its plastic zone is obviously distributed in the inner part of the coal seam and the mudstone layer in the upper part of the coal seam, showing penetrability. Moreover, the plastic failure depth of roof at different locations is different, and the plastic failure depth of roof at coal pillar side is obviously greater than that at cutting coal side, which is highly consistent with the distribution characteristics of roof subsidence in field roadway. Figure $6 \mathrm{c}$ is the actual photograph of roof deformation about $300 \mathrm{~m}$ behind the coal face of the panel 81305 No.2 return airway in Baode coal mine. The deformation of roof on the coal pillar side reaches $450 \mathrm{~mm}$, and the degree of deformation is obviously greater than that on the cutting coal side. The deformation magnitude of roof corresponds to the depth of roof failure.

Since the plastic failure is essentially compression-shear failure, the rock surface under compression-shear is usually rough, and the rock surface under tension is smooth. Based on this, the distribution of plastic zone in the panel 81305 No.2 return airway in the Baode coal mine is detected by using roof dense boreholes. The detection location is $400 \mathrm{~m}$ behind the panel 81305 , and the roof deformation at this location is close to the maximum, as shown in Figure 3. The peep depth is $8.0 \mathrm{~m}$, and five groups of detection holes are evenly arranged in the same section. Because of the serious deformation and damage of roadway surrounding rock, the borehole peep should be carried out in time after the hole is formed, and the shallow hole protection should be carried out to prevent the phenomenon of hole collapse.

The detection results also show that the plastic zone of surrounding rock will penetrate through the strata without plastic failure and redistribute in the upper strata with lower strength. Thus the shallow plastic zone and penetrating plastic zone appear. The shallow plastic zone shows in the shallow part of coal seam. From the roof on the coal pillar side of the roadway to the roof on the cutting coal side of roadway, the failure depth of the shallow plastic zone is successively $2418,2518,2076,1530$ and $1168 \mathrm{~mm}$, and the shallow plastic zone has non-uniformity, which has a maximum depth toward the roof, as shown in Figure 7a. The plastic zone penetration starts from the thin mudstone layer 
above the coal seam, and all the thin mudstone layer is destroyed within the scope of peeping. At the same time, local damage occurred on the sandy mudstone layer, and the maximum damage depth occurred on the coal pillar side, which was $735 \mathrm{~mm}$ from the upper boundary of the coal seam. The rock formation without plastic failure between the high penetrating plastic zone and the shallow plastic zone has a few cracks. And the damage surface is relatively smooth. The on-site plastic zone detective results are almost consistent with the on-site deformation observation and numerical simulations, as shown in Figure 7.

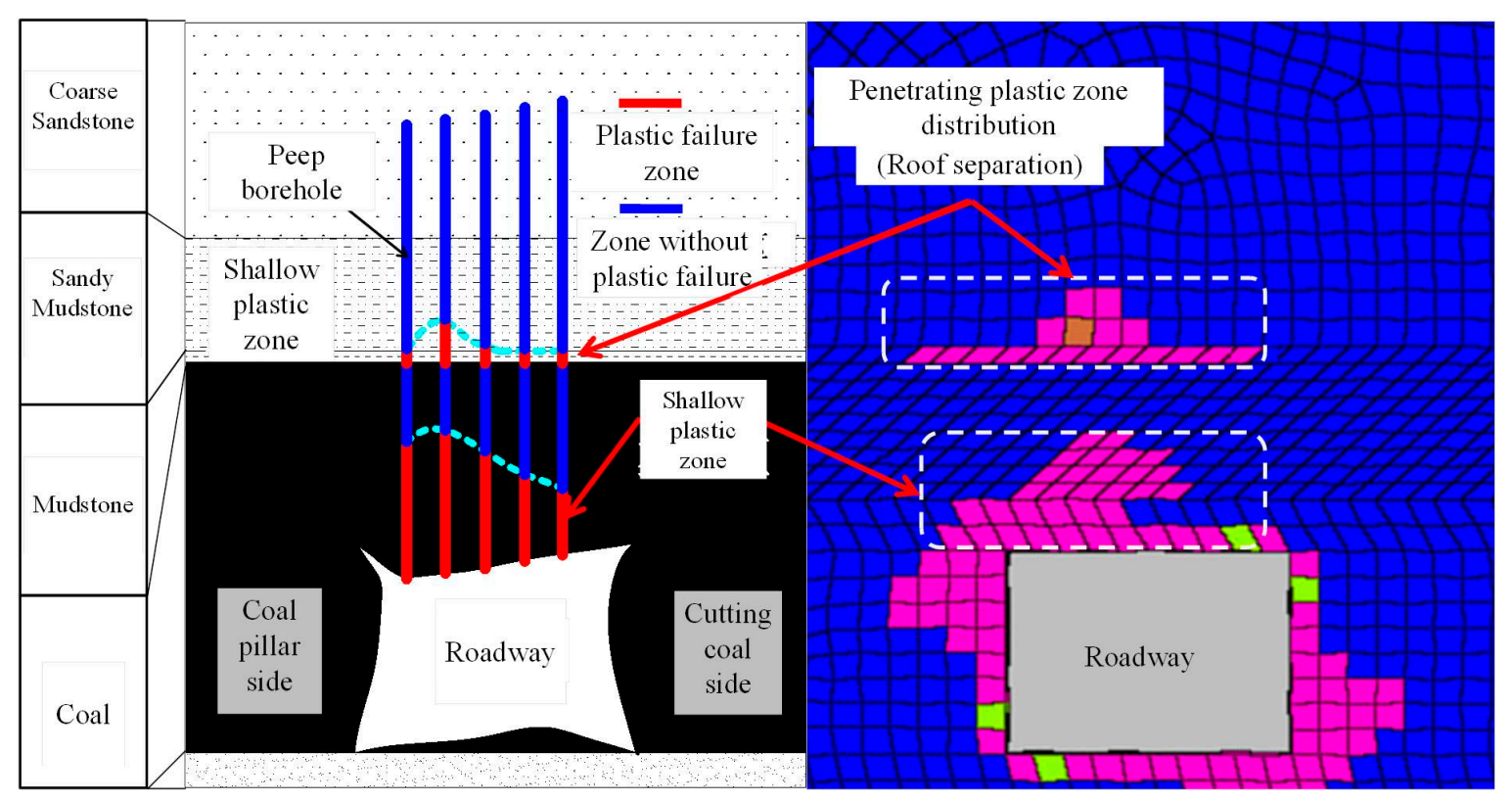

(a) Field detection results

(b) Numerical simulation results

Figure 7. Comparison of numerical simulation and actual measurement results of plastic failure zone of roof after mining in the panel 81305 No. 2 return airway.

\subsection{Measurement of Plastic Failure Development of Roadway Roof during Mining}

\subsubsection{High-Density Deep Displacement Monitoring Scheme of Roof}

In the actual situation, the detection of plastic zone expansion is extremely difficult. However, the surrounding rock deformation of the roadway is mainly caused by the plastic failure, but the deformation of the surrounding rock in the elastic zone is extremely small, generally less than $5 \%$, and most of the deformation is caused by the surrounding rock failure. This penetrating development characteristic of the plastic zone can be reflected by the deformation mechanisms of each layer of the roof, and accordingly, the high-density deep displacement monitoring method of the roof is adopted.

The key to the deep displacement monitoring method of high-density roof is: (1) The sensor used in the monitoring instrument needs to have certain precision and can perform stable and reliable real-time monitoring; (2) Perform deep displacement monitoring of surrounding rock, and arrange with sufficient displacement base points. In this way, people can accurately observe the deformation of surrounding rock at different depths and the timing of its deformation. The monitoring instrument adopts the high precision and multi-base point roadway roof deep displacement monitoring instrument, as shown in Figure 8. The instrument is designed separately and consists of a mechanical deep base displacement amplifier and a secondary instrument. The secondary instrument has installed large capacity data storage module and wireless transmission device. The accuracy of the mechanical deep base displacement amplifier can reach $0.2 \mathrm{~mm}$. 


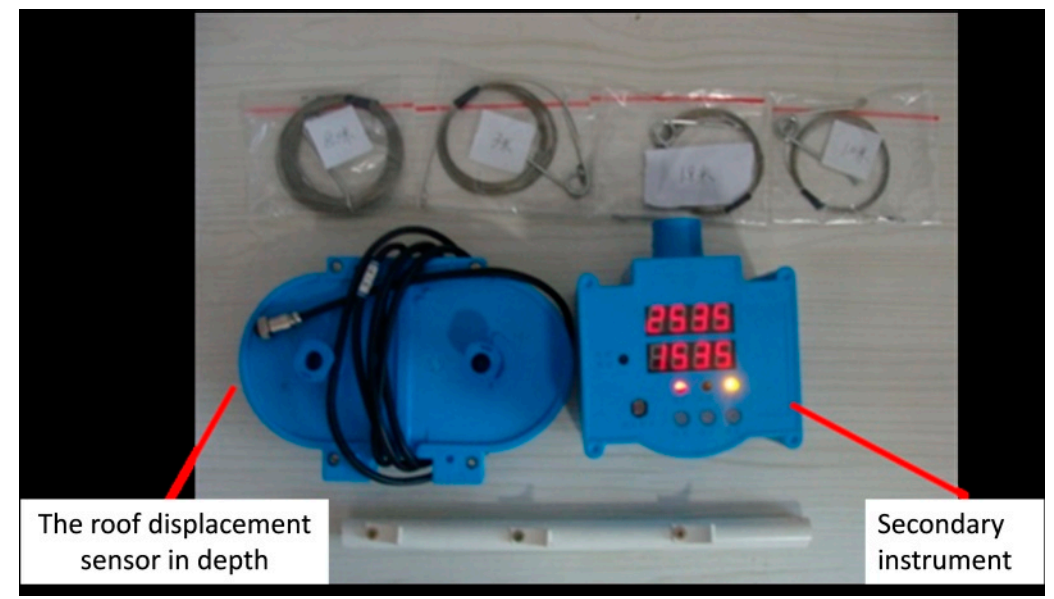

Figure 8. Separate multiple basic points deep displacement monitor.

The scheme of joint arrangement of the multi-point separating layer monitor for roadway roof is adopted. Each monitor has four displacement base points, while the joint arrangement has eight displacement basic points. Because a single borehole cannot be arranged with too many displacement basic points, a split borehole arrangement is adopted to prevent the displacement base line from intertwining during the installation, as shown in Figure 9.

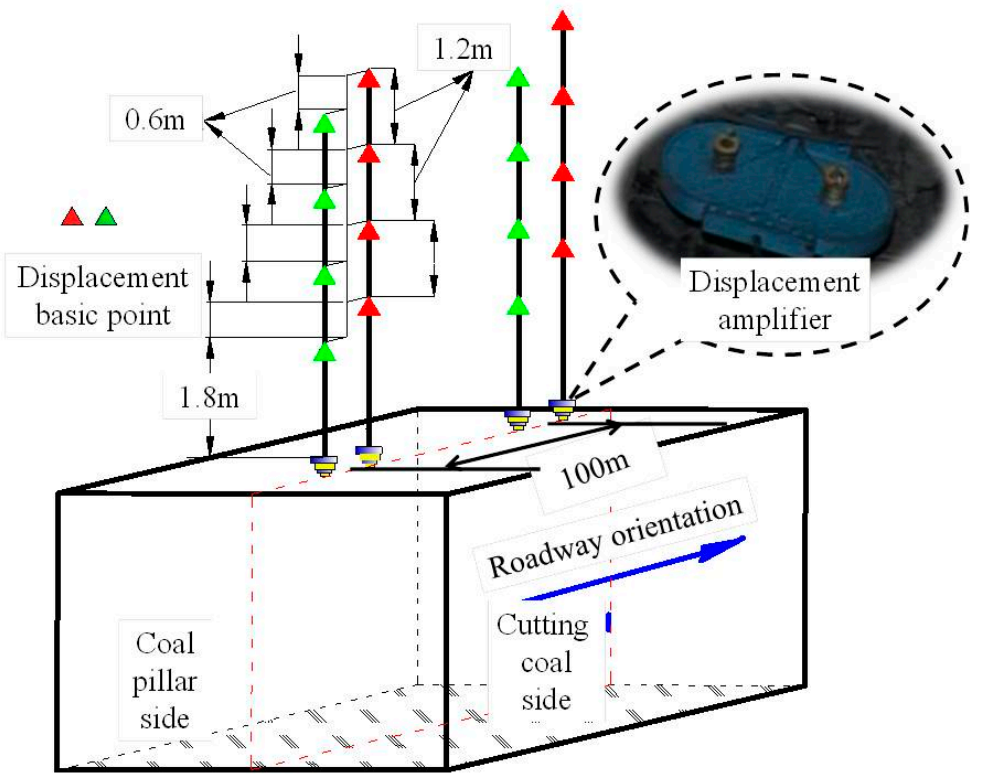

Figure 9. Displacement base point arrangement scheme of high-density deep displacement monitor of roadway roof.

Each station is equipped with two boreholes with a distance of about $0.5 \mathrm{~m}$ along the roadway. The borehole is located in the center of the roadway, and the deepest displacement base point is $6.0 \mathrm{~m}$ (far exceeding the maximum plastic failure depth of $4.1 \mathrm{~m}$ shown in Figure 7a). Then each borehole is equipped with four base points, and the eight base points are evenly spaced. The minimum spacing density is $0.6 \mathrm{~m}$, as shown in Table 2 . 
Table 2. Arrangement of displacement base point depth in high-density deep displacement monitoring of roof.

\begin{tabular}{|c|c|c|c|c|c|c|c|c|}
\hline Borehole Location & & & & sic Po & Depth/ & & & \\
\hline Borehole A & 1.8 & - & 3.0 & - & 4.2 & - & 5.4 & - \\
\hline Borehole B & - & 2.4 & 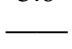 & 3.6 & 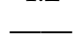 & 4.8 & 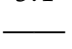 & 6.0 \\
\hline
\end{tabular}

According to the mining situation in the Baode coal mine, two survey stations are selected to monitor the deformation of surrounding rock in the adjacent panel 81306 No.2 return airway at $2400 \mathrm{~m}$ and $2500 \mathrm{~m}$ from the roadway entrance. At the beginning of monitoring, station I is located $200 \mathrm{~m}$ behind the panel 81305 and station II is $100 \mathrm{~m}$ behind the panel 81305 . Figure 10 shows the layout scheme of high-density deep displacement monitoring station of the roof.

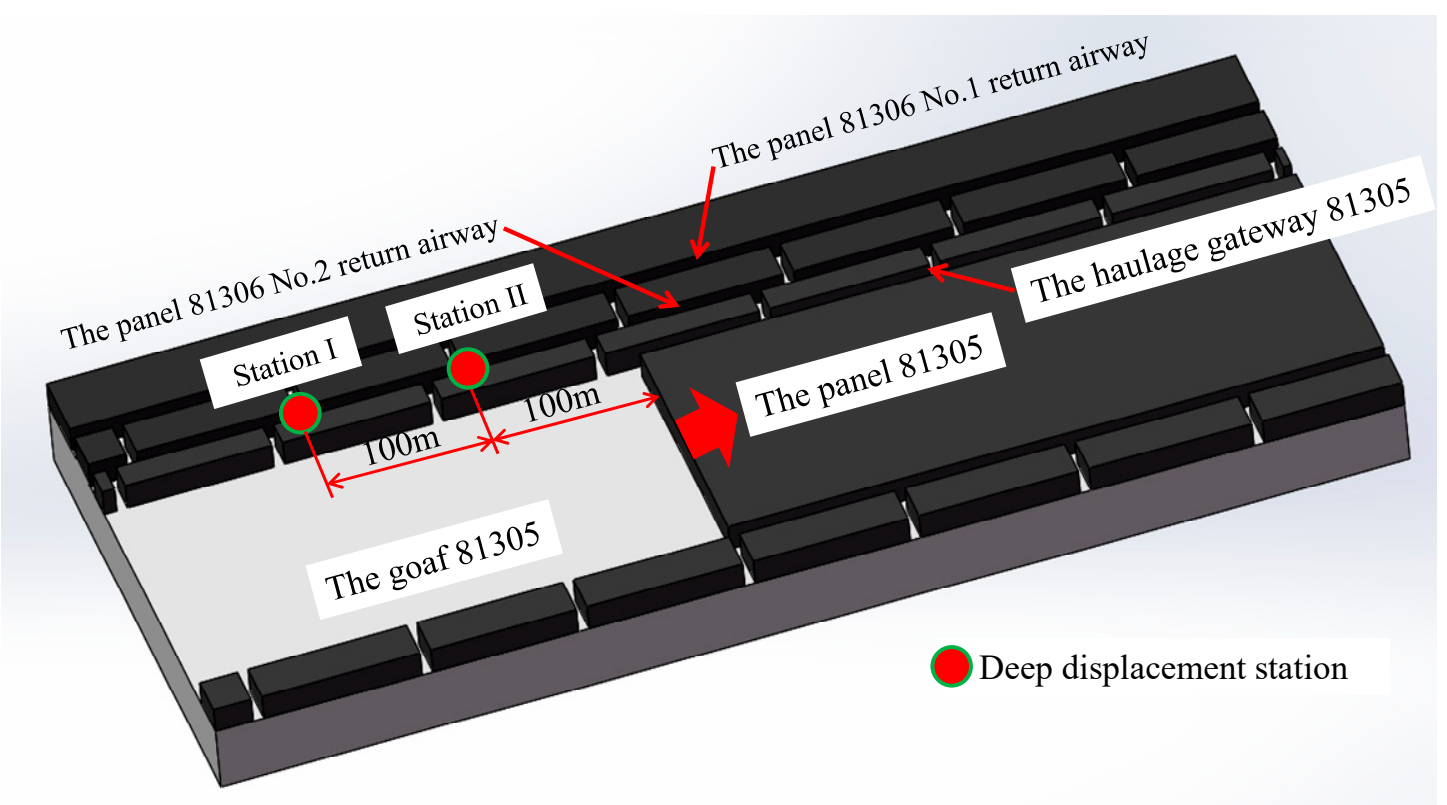

Figure 10. Layout scheme of high-density deep displacement monitoring of roof.

\subsubsection{Monitoring Results and Analysis}

Figure 11 shows the high-density deep displacement monitoring curve of roadway roof of station I. When the monitoring started, the station was located $200 \mathrm{~m}$ behind the coal face, and the monitoring lasted for 35 days in total. The total displacement quantity of the station was $512.2 \mathrm{~mm}$. The overall trend of roof deformation can be roughly distributed into three stages: the stationary stage before the intense mining, the stage of the influence of intense mining, and the stationary stage after the mining. On the fourth day of monitoring, the deformation rate of the roof is accelerated. At this moment, the monitoring station I is located about $250 \mathrm{~m}$ behind the coal face. On the 18th day of monitoring, the roof deformation tends to be stable. At this moment, the monitoring station I is located about $440 \mathrm{~m}$ behind the coal face. The roof deformation tends to be stable after the panel advances $440 \mathrm{~m}$.

During the monitoring period, the deformation amount of each strata and its proportion of the total deformation is shown in Table 3. Among them, the total deformation amount in the range of $0-1.8 \mathrm{~m}$ is the largest. It reaches $148.8 \mathrm{~mm}$ and accounts for $29 \%$ of the total deformation. Because of the large range of the layer and its location in the top surface of the roof. Among the roof's depth over $1.8 \mathrm{~m}, 1.8-2.4 \mathrm{~m}$ and 3.6-4.2 $\mathrm{m}$ have the largest deformation, accounting for $18 \%$ and $17 \%$ of the total deformation, respectively. Combined with the observation results of the plastic failure zone of the roof in Figure 7a, it can be inferred that the deformation of these two layers is mainly caused by plastic failure and the crushing deformation of surrounding rock. The deformation in layers of 
4.8-5.4 $\mathrm{m}$ and 5.4-6.0 $\mathrm{m}$ accounts for only $4 \%$ and $2 \%$ of the total deformation, respectively. It can be considered that the elastic zone of surrounding rock is above $4.8 \mathrm{~m}$, and the weak deformation in this area is elastic deformation. The deformation in layer of $4.2-4.8 \mathrm{~m}$ is $56.8 \mathrm{~mm}$, which accounts for $11 \%$ of the total displacement. The main reason is that the elastic-plastic interface of the roadway roof is located in this layer, and the deformation is mainly caused by the extension of the partially penetrating development of plastic zone. The deformation in 2.4-3.0 m and 3.0-3.6 m layers accounted for $11 \%$ and $7 \%$ of the total deformation, respectively, and the deformation was small. The main reason was that the coal and rock without plastic failure is between shallow plastic zone and high penetrating plastic zone, which was mainly caused by the strong expansion pressure accompanied by penetrating plastic failure in mudstone layer. From the perspective of the time when the deformation of surrounding rock occurs in each strata of roof, the deformation of surrounding rock in $2.4-3.0 \mathrm{~m}$ and $3.0-3.6 \mathrm{~m}$ layers is relatively lagging behind. The main reason is that the deformation and failure of roof in this area mainly originates from the expansion of high-penetrating plastic zone, and the "passive" failure is the main one.

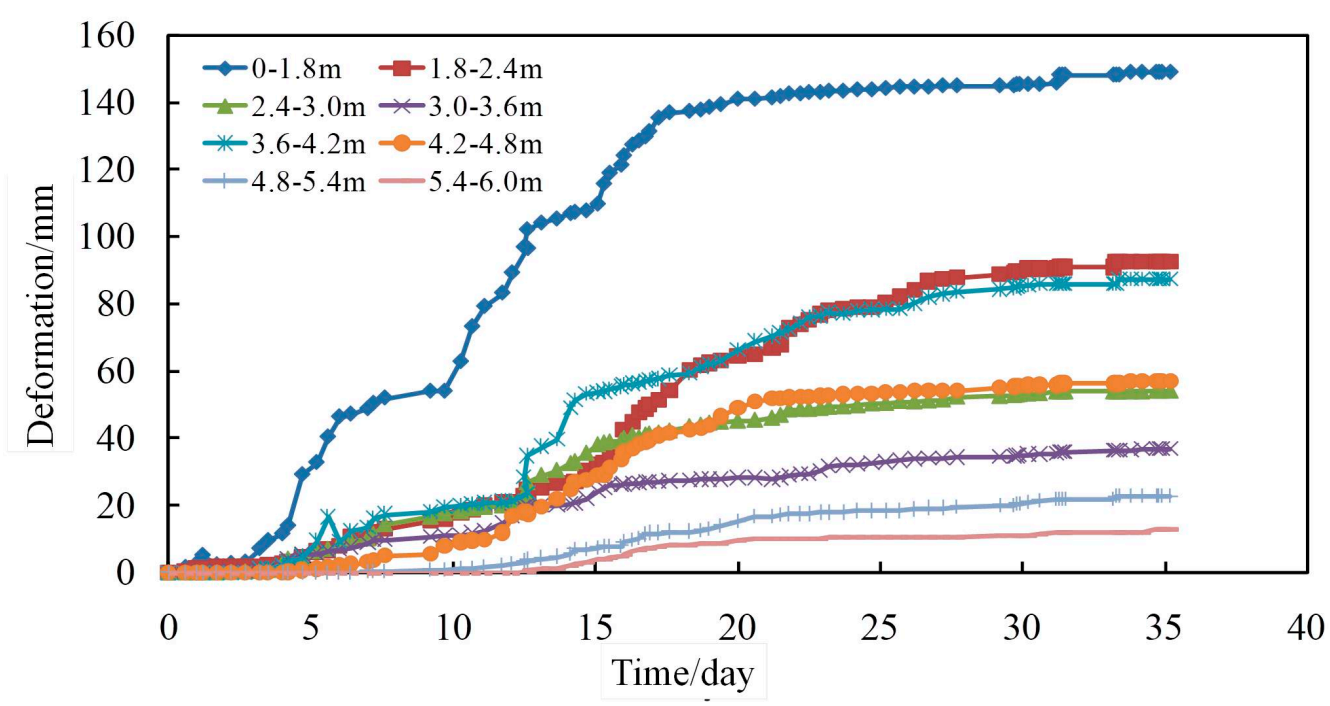

Figure 11. Curves of roadway roof deep displacement of Station I.

Table 3. Distribution of roof deformation in each layer of Station I.

\begin{tabular}{ccccccccc}
\hline Layer/m & $0-1.8$ & $1.8-2.4$ & $2.4-3.0$ & $3.0-3.6$ & $3.6-4.2$ & $4.2-4.8$ & $4.8-5.4$ & $5.4-6.0$ \\
\hline Deformation amount/mm & 148.8 & 92.6 & 54.2 & 37.0 & 87.4 & 56.8 & 22.8 & 12.8 \\
Proportion of total deformation & $29 \%$ & $18 \%$ & $11 \%$ & $7 \%$ & $17 \%$ & $11 \%$ & $4 \%$ & $2 \%$ \\
\hline
\end{tabular}

Figure 12 shows the high-density deep displacement monitoring curve of roadway roof of station II. When the monitoring starts, the station is located $100 \mathrm{~m}$ behind the coal face. During the monitoring period, the total displacement of the station is $569.8 \mathrm{~mm}$, and the deformation mechanisms of the roof are almost the same as that of the station I. Among them, the intense mining influence stage occurs in the $210-420 \mathrm{~m}$ range behind the coal face. The deformation of each layer of the roadway and its ratio of the overall deformation is shown in Table 4. Compared with the station I, the deformation of the $1.8-2.4 \mathrm{~m}$ and $3.6-4.2 \mathrm{~m}$ is larger, accounting for $22 \%$ and $22 \%$ of the total deformation respectively. It can be inferred that the deformation of these two layers is mainly caused by the development and extension of the shallow plastic zone and the penetrating plastic zone. The deformation in 2.4-3.0 m and 3.0-3.6 m layers accounted for $11 \%$ and $8 \%$ of the total deformation respectively. It was also caused by the fracture of the medium strata because of the expansion of the deep penetrating plastic zone. 


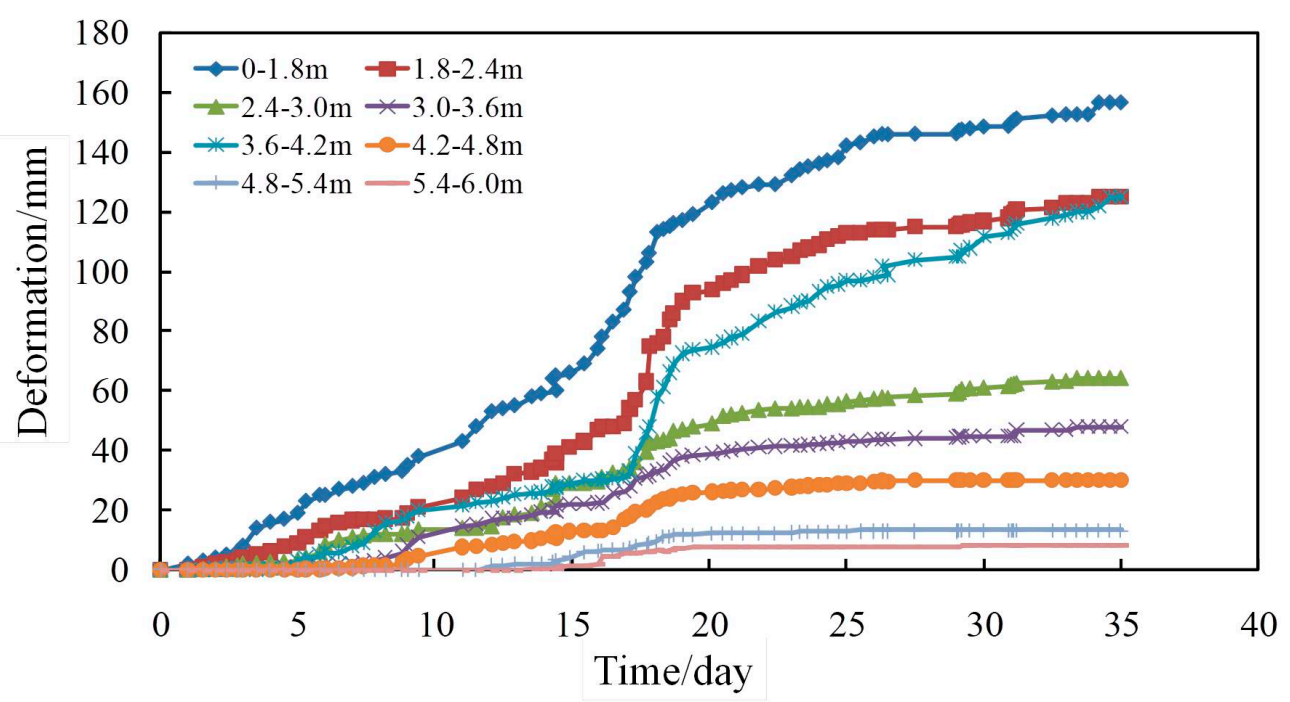

Figure 12. Curves of roadway roof deep displacement of Station II.

Table 4. Distribution of roof deformation in each layer of Station II.

\begin{tabular}{ccccccccc}
\hline Layer/m & $0-1.8$ & $1.8-2.4$ & $2.4-3.0$ & $3.0-3.6$ & $3.6-4.2$ & $4.2-4.8$ & $4.8-5.4$ & $5.4-6.0$ \\
\hline Deformation amount/mm & 156.4 & 125.2 & 64.2 & 47.8 & 125.0 & 29.8 & 13.4 & 8.4 \\
Proportion of total deformation & $27 \%$ & $22 \%$ & $11 \%$ & $8 \%$ & $22 \%$ & $6 \%$ & $2 \%$ & $2 \%$ \\
\hline
\end{tabular}

\section{Mechanical Analysis of Deformation and Failure of Roadway Compound Roofs}

Combining the measured and simulated results of the roof rupture before and after mining with the measured results of plastic failure development of roadway roof during mining, it can be seen that the plastic failure of compound roof of the panel 81305 No.2 return airway first occurs in the roof of shallow coal seam and evolves continuously. With the continuous mining of the coal face, the roof failure does not appear to be the "layer by layer failure" in the traditional theory, but it penetrates the thin mudstone layer and sandy mudstone layer above the coal seam. The forming process of the deep penetration plastic zone accompanied by strong deformation pressure. It has a huge compression effect on the middle of the roof without plastic failure, leading to the fracture failure mainly caused by pull-out for the middle rock layer.

The coal mining leads to the increase of two principal stresses, the continuous increase of the two principal stresses ratio and the continuous change of principal stress direction around the surrounding rock of roadway. These are the main reasons for the irregular distribution in the plastic zone of the compound roof of the roadway. Figure 13 shows the development process of the plastic zone of the compound roof of the mining roadway in the Baode coal mine and its corresponding stress conditions. $\sigma_{1} / \sigma_{3}$ is the ratio of the maximum principal stress to the minimum principal stress, and $\beta$ is the angle between the maximum principal stress and the vertical direction. Figure 14 is a schematic diagram of the overall deformation and failure development process of the compound roof of the mining roadway in the Baode coal mine. The deformation and failure process of the compound roof of the roadway is mainly divided into four stages:

(1) The formation of the initial plastic zone. Under the action of the primary rock stress, after the roadway is completed, a small-scale plastic failure occurs in the surrounding rock. As shown in Figures 13a and 14a, the deformation of surrounding rock is also small and easy to support.

(2) The expansion of the shallow plastic zone. The coal mining leads to the increase of two principal stresses, the increase of two principal stress ratio and the continuous change of principal stress direction around the surrounding rock of roadway. These will lead to the non-uniform expansion 
of shallow plastic zone, accompanied by the non-uniform deformation of roof, as shown in Figures $13 \mathrm{~b}$ and $14 \mathrm{~b}$.

(3) The formation and expansion of the deep penetration plastic zone. With the further mining of the coal face, the two principal stresses and the directions of the two principal stresses are constantly changing, resulting in the continuous expansion of the plastic zone of the roof and the plastic zone "cross" the median rock layer with higher strength. It forms the penetrating plastic zone preferably in the deep weak rock layer. Meanwhile shallow plastic zone also continues to expand. As shown in Figures 13c and 14c, the destruction of the thin mudstone layer at this stage is the separation phenomenon of the roadway roof.

(4) Fracture of the middle strata without plastic zone failure, and the formation and expansion of the deep penetrating plastic zone. As shown in Figure 13d, with tremendous expansion and deformation pressure, a tremendous compressive load is formed on the middle plastic zone, which results in the normal stress at a point in the lower part of the rock strata without plastic failure exceeds its tensile strength. There will be fracture failure, or even complete instability. The fracture failure in the middle strata generally lags behind the formation of the deep penetrating plastic zone, as shown in Figure 14d. During the period, the surrounding rock of the roadway has severe non-uniformity and large deformation, and the support is extremely difficult. It is required to have a kind of high-strength support material with an anchorage range larger than the depth of the penetrating plastic zone and not broken during the deformation process.

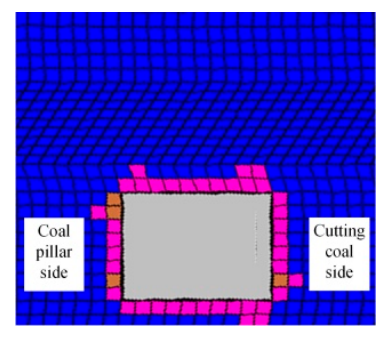

$\sigma_{1} / \sigma_{3}=1.0, \beta=0^{\circ}$

(a) The formation of the initial plastic zone.

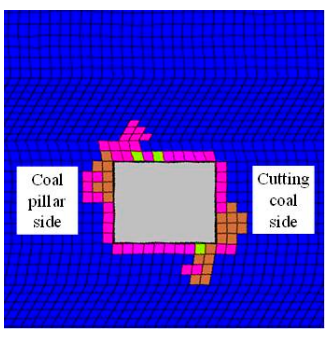

$\sigma_{1} / \sigma_{3}=2.0, \beta=35^{\circ}$

(b) The expansion of the shallow plastic zone.

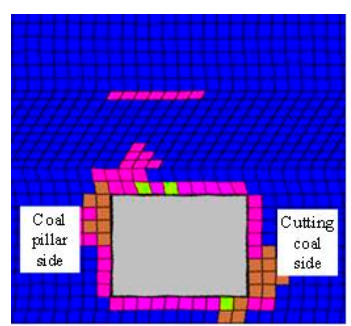

$\sigma_{1} / \sigma_{3}=2.5, \beta=40^{\circ}$

(c) The formation and expansion of the deep penetration plastic zone.

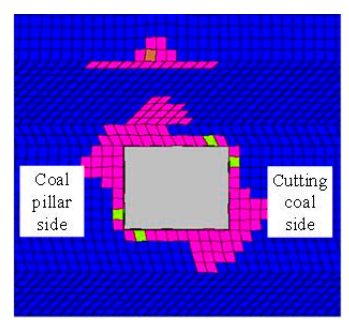

$\sigma_{1} / \sigma_{3}=3.0, \beta=46^{\circ}$

(d) Fracture of the

middle strata without plastic zone failure.

None

shear-p

\section{shear-p tension-p}

Figure 13. Plastic zone development process of roadway compound roof.

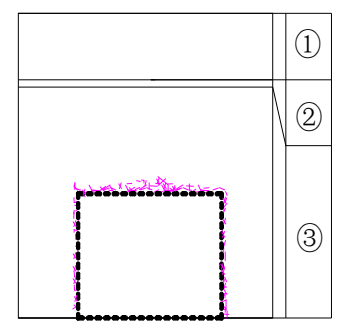

(a)

(1) Sandy Mudstone

(4)

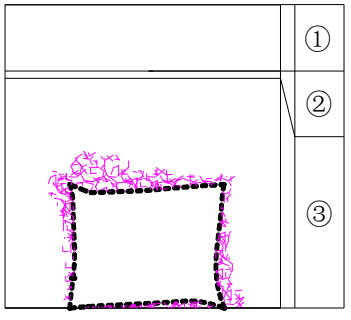

(b)

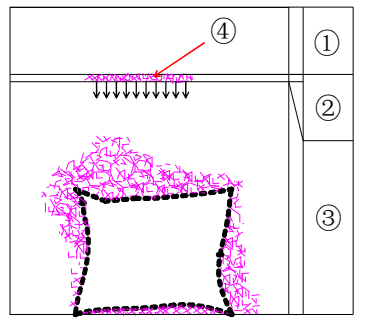

(c)
(2) Thin Mudstone

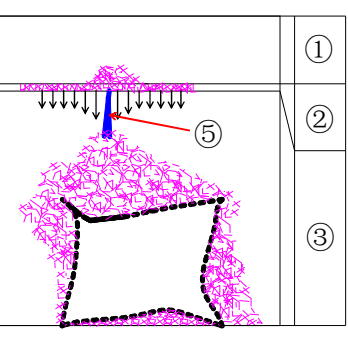

(d)

(3) Coal

(5) $\square$ Fracture damage

Figure 14. Deformation and failure development process of roadway compound roof. 


\section{Field Application and Effect Analysis}

According to the plastic zone penetration development of the compound roof of the mining roadway, roofs at different positions have different rupture forms, and the formation and expansion of the deep penetration plastic zone is the top priority of the roof control. Based on this, a roof hierarchical support method mainly based on roof control is proposed: the auxiliary support material prevents the surface fragmentation of the roof from falling within $0.5 \mathrm{~m}$; ordinary long-extension bolts are arranged with a high density arrangement, which is adopted to control the surrounding rock in the shallow plastic zone within the range of $1.5-2.0 \mathrm{~m}$. The surrounding rock in the penetrating plastic zone within 3.0-4.0 m with the long-extension bolts is stable, avoiding the dangerous instability of the roof. The long-term anchorage is used to control the large-area instability collapse of the roof in time. The surrounding rock strata in the plastic zone is re-reinforced.

Field tests were carried out in No.1 and No.2 return airways of the panel 81306 of the Baode coal mine. The hierarchical support plan of the roadway roof is shown in Table 5. During the roadway excavation, the support parameters are $2 \Phi 17.8 \times 6500 \mathrm{~mm}$ anchor cable $/ \mathrm{m}$ and $4 \Phi 20 \times 2200 \mathrm{~mm}$ anchor/m, auxiliary material selection $1200 \times 4700 \mathrm{~mm}$ steel frame lead wire mesh. According to the measured results of plastic failure depth of the roof, before the impact of the mining, the roof of the roadway is supplemented with $4 \Phi 20 \times 5000 \mathrm{~mm}$ long anchors to control the surrounding rock in the plastic zone. The length of the test roadway is $200 \mathrm{~m}$, which is arranged in two sections, each section is $100 \mathrm{~m}$, the two test roadways are separated by $200 \mathrm{~m}$.

The $5 \mathrm{~m}$ long-extension bolt consists of two $2.5 \mathrm{~m}$ rod parts, which are butted with a special connection joint to solve the restriction of bolt length in roadway space. Fixing and connecting the bolt in subsection during construction allowed for sufficient extension, and a special connecting joint was assembled from a rod body diameter-extension structure and connected via a wire column with a high intensity. The structure of the long-extension bolt is shown in Figure 15. The long-extension mainly inhibits the formation and expansion of the high penetrating plastic zone, so it is all right to construct just before the mining, and the drilling speed can be greatly increased.

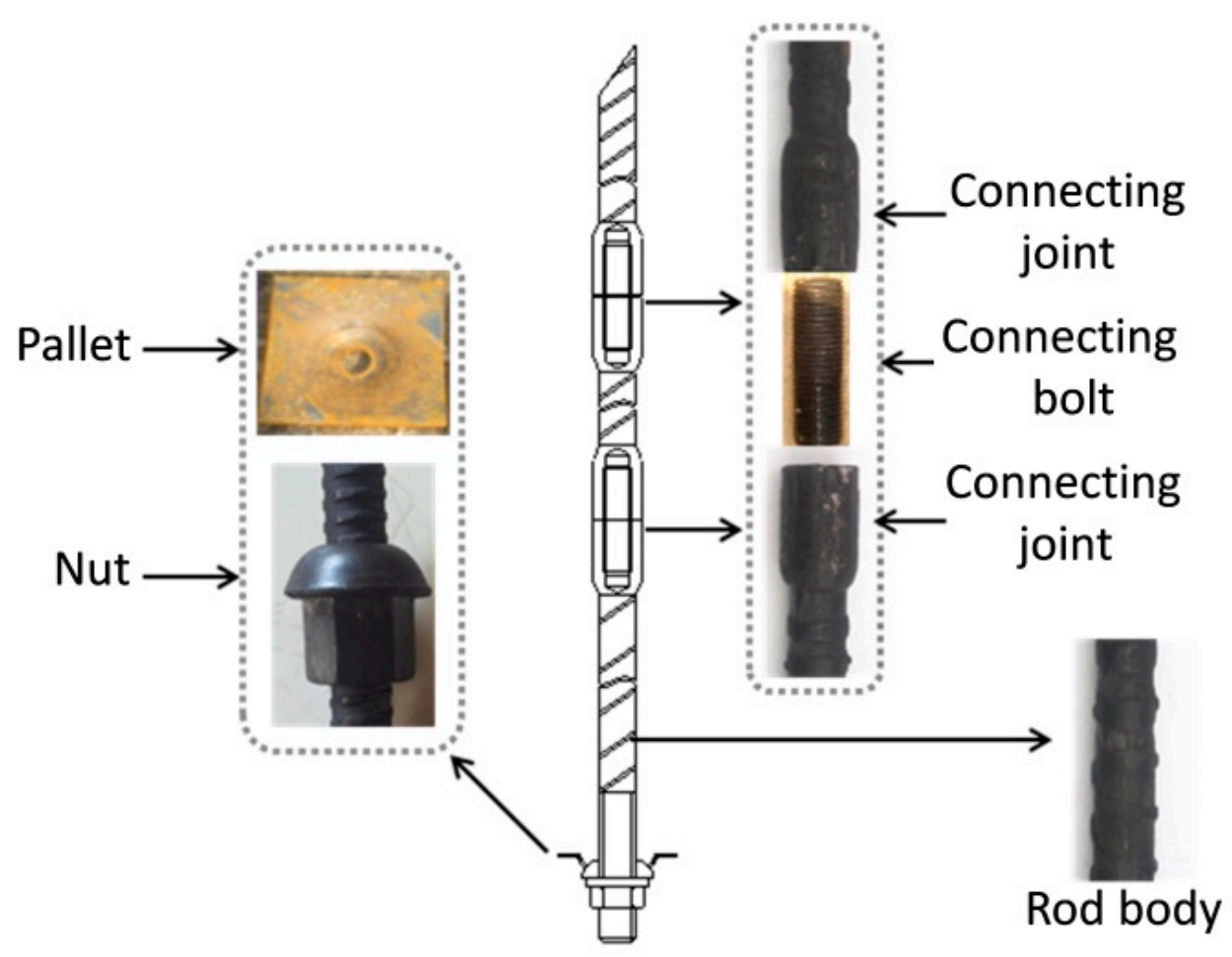

Figure 15. Structural composition of long-extension bolt. 
Table 5. Supporting programs and parameters in test roadway.

\begin{tabular}{|c|c|c|c|c|}
\hline Level & Control Target & Support Material & Support Density & Support Timing \\
\hline First & surface crushed rock falling & $\begin{array}{c}1200 \times 4700 \mathrm{~mm} \text { steel } \\
\text { skeleton lead wire mesh }\end{array}$ & $\begin{array}{l}8 \# \text { wire } / 45 \times 45 \mathrm{~mm} \\
\text { grid }\end{array}$ & when excavating \\
\hline Second & $\begin{array}{c}\text { shallow plastic zone, local } \\
\text { leaking roof }\end{array}$ & $\varphi 20 \times 2200 \mathrm{~mm}$ bolt & 4 bolts $/ \mathrm{m}$ & when excavating \\
\hline Third & Deep penetration plastic zone & $\varphi 20 \times 5000 \mathrm{~mm}$ bolt & 4 bolts $/ \mathrm{m}$ & before mining \\
\hline Fourth & $\begin{array}{c}\text { large-scale instability of deep } \\
\text { roof }\end{array}$ & $\Phi 21.6 \times 8000 \mathrm{~mm}$ anchor & 2 anchors $m$ & when excavating \\
\hline
\end{tabular}

After the first mining and before the second mining, when the roof deformation tends to be stable, the roof subsidence of the panel 81306 No.2 return airway with large deformation is counted. As shown in Figure 16, the maximum, minimum and average roof subsidence are $1200 \mathrm{~mm}, 200 \mathrm{~mm}$ and $630 \mathrm{~mm}$, respectively.

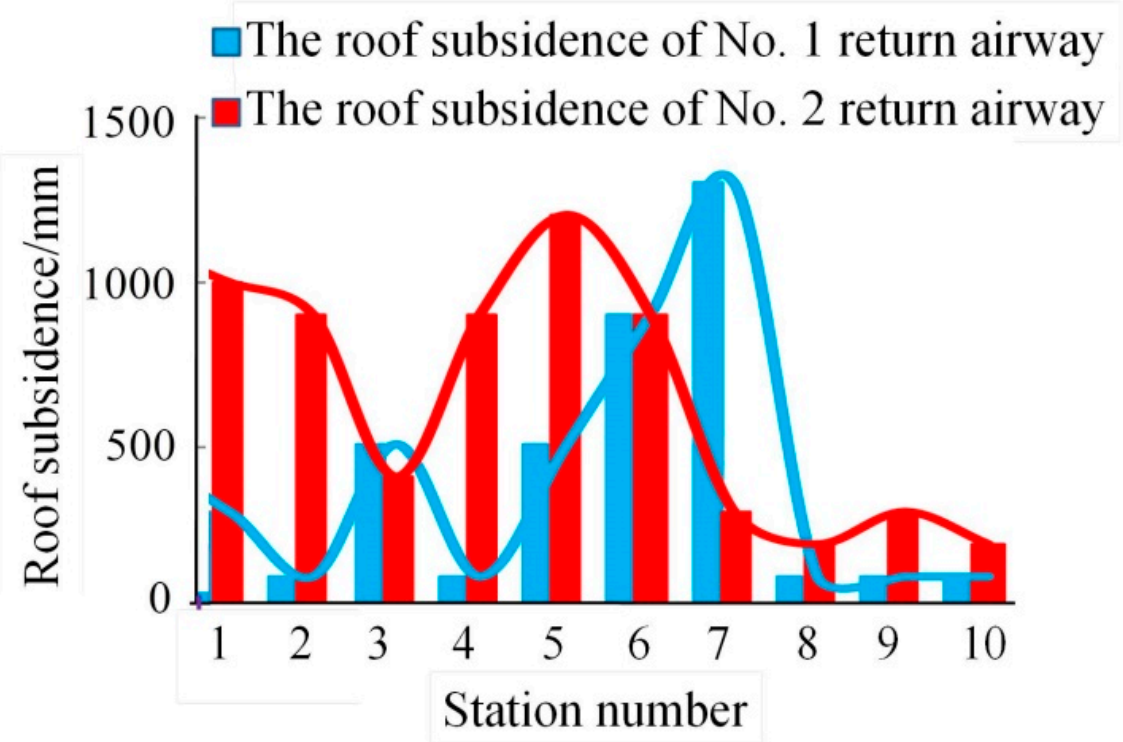

Figure 16. Monitoring statistics of roof subsidence in the test roadway.

In order to grasp the working state of long-extension bolts, a bolt support force monitoring instrument is used to monitor the supporting force of long-extension bolt in the test section. Six groups of measuring stations (three bolt tension sensors for each group) are set up at equal intervals in the test section. Because there are four bolts in each row, three bolt tension sensors randomly monitor three of them and record the supporting force of roadway roof of long-extension bolts during the dynamic influence period. The statistical results of average supporting resistance of long-extension bolt are shown in Figure 17. Statistical results show that the long-extension bolt has reached its proper working state, and the breakage rate of the long-extension bolt is only $3 \%$, showing good support stability. 


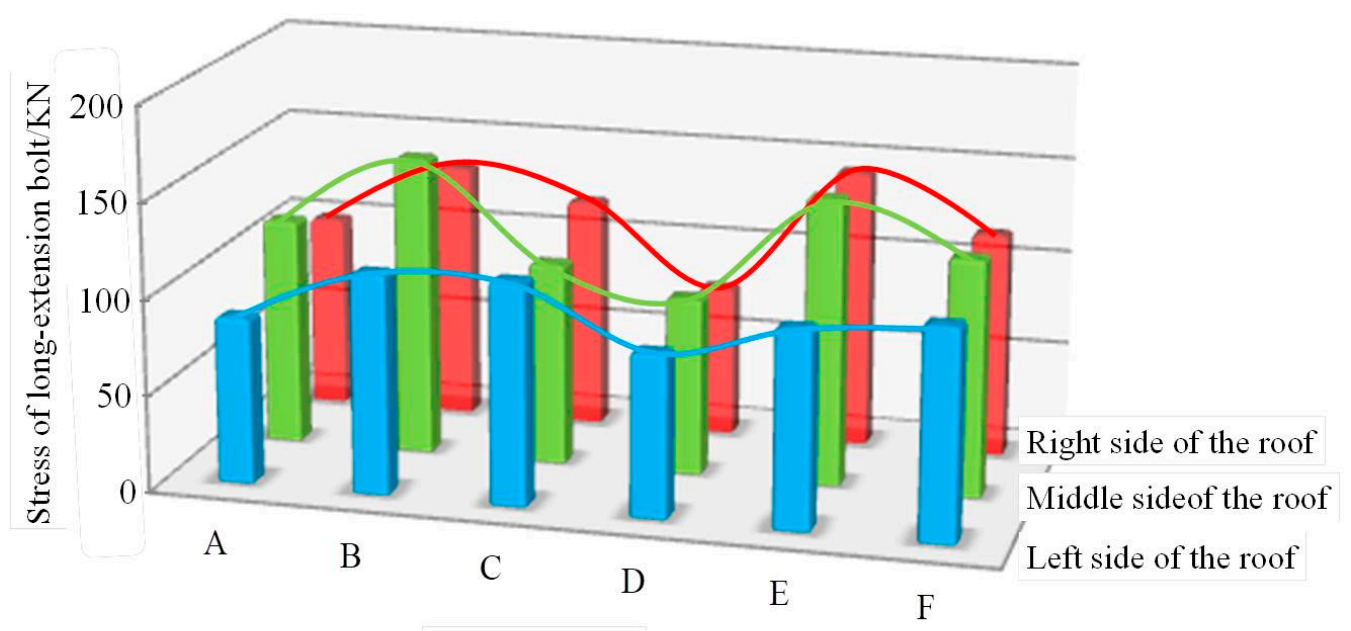

Station number

Figure 17. Monitoring statistics of long-extension bolt support force in the test roadway.

\section{Conclusions}

According to field monitoring, numerical simulation and theoretical analysis, the development characteristics and deformation mechanisms of the compound roof of roadways are revealed. The coal face mining causes the increase of the two principal stresses, the ratio of principal stress around the surrounding rock of the roadway, and the principal stress direction is also constantly changing. This is the main reason for the irregular distribution of the plastic zone of the roadway compound roof. During the expansion of the plastic zone, the plastic zone will "cross" the higher-strength rock strata to redistribute in the lower-strength rock strata, forming a deep penetration plastic zone. According to the distribution rules and production mechanisms of the roof plastic zone in different strata, the development process of the plastic zone of the roadway in the compound roof are divided into four stages. Stage I is the formation of the initial plastic zone. Stage II is the expansion of the shallow plastic zone. Stage III is the formation and expansion of the deep penetration plastic zone. Stage IV is the fracture of the rock strata without the plastic zone failure in the middle. Fracture of the middle strata without plastic zone failure is caused by the formation and expansion of the deep penetrating plastic zone.

However, the severe deformation of the roadway roof is mainly caused by plastic failure. The severe deformation of the $8 \#$ coal seam mining roadway roof in the Baode coal mine is mainly caused by plastic failure. The deformation caused by the shallow plastic zone and the deep penetration plastic zone of the roof can reach more than $75 \%$ of the total deformation. The deformation of the rock strata with no plastic failure in the middle accounted for less than $20 \%$ of the total deformation, and the deformation timing lags behind the appearance of the deep penetration plastic zone. The main reason of deformation amount distribution is that the formation and expansion of the penetrating plastic zone is accompanied by severe deformation pressure, which leads to fracture and tension failure of rock strata located in the middle without plastic failure, and its instability depends on the extension degree of the deep penetrating plastic zone.

According to the penetration development of the plastic zone in compound roof of the mining roadway, the hierarchical support design led by the long-extension bolt is carried out on the test roadway. The monitoring results show that the application effect is good. The long-extension bolt support can restrain the malignant expansion of the deep penetration plastic zone and improve the speed of roadway support. At the same time, the control of auxiliary material support to the surface roof, the control of high-density short bolt to the shallow roof and the control of large-scale collapse of deep roof by long cable bolt during roadway excavation are all effective. 
Author Contributions: Conceptualization, H.J.; Methodology, K.P.; Software K.P.; Validation, K.P., B.P. and K.F.; Formal Analysis, K.P.; Investigation, K.F.; Resources, S.L. and B.P.; Data Curation, B.P. and K.F.; Writing-Original Draft, K.P.; Writing—Review \& Editing, H.J. and S.L.; Visualization S.L.; Supervision, H.J.; Project Administration, L.W.

Funding: This research was funded by National Natural Science Foundation of China, grant number 51604094 and 51674098 and The APC was funded by National Natural Science Foundation of China.

Acknowledgments: This work was supported by the National Natural Science Foundation of China (Grant Nos. 51604094, 51674098).

Conflicts of Interest: The authors declare no conflict of interest.

\section{References}

1. Zhang, C.; Zhou, H.; Feng, X. An Index for Estimating the Stability of Brittle Surrounding Rock Mass: FAI and its Engineering Application. Rock Mech. Rock Eng. 2011, 44, 401-414. [CrossRef]

2. Jiang, L.; Mitri, H.S.; Ma, N.; Zhao, X. Effect of foundation rigidity on stratified roadway roof stability in underground coal mines. Arab. J. Geosci. 2016, 9, 1-12. [CrossRef]

3. Aziz, N.; Craig, P.; Mirzaghorbanali, A. Factors Influencing the quality of encapsulation in rock bolting. Rock Mech. Rock Eng. 2016, 49, 3189-3203. [CrossRef]

4. Aziz, N.; Hillyer, J.; Joyce, D.; Ma, S.; Nemcik, J.; Moslemi, A. New approach to resin sample preparation for strength testing. In Proceedings of the 13th Underground Coal Operators Conference, Wollongong, Australia, 14-15 February 2013; pp. 152-155.

5. Aziz, N.; Jalalifar, H.; Concalves, J. Bolt surface configurations and load transfer mechanism. In Proceedings of the 7th Underground Coal Operators Conference, Coal 2006, Wollongong, Australia, 5-7 July 2006; pp. 236-244.

6. Ma, S.; Aziz, N.; Nemcik, J.; Mirzaghorbanali, A. The effects of installation procedure on bond characteristics of fully grouted rock bolts. Geotech. Test J. 2017, 40, 846-857. [CrossRef]

7. Zhang, X.; Li, Q.; Huang, K.; Li, G. Study of coupling support for large-span coal roadway under mining dynamic load and its application. J. Rock Mech. Eng. 2014, 1, 60-68.

8. Zhang, Z.; Wang, W.; Li, S.; Bai, J.; Hao, S.; Wu, H.; Yu, X. An innovative approach for gob-side entry retaining with thick and hard roof: A case study. Tech. Gazette 2018, 25, 1028-1036.

9. Zhang, Z.; Yu, X.; Wu, H.; Deng, M. Stability Control for Gob-Side Entry Retaining with Supercritical Retained Entry Width in Thick Coal Seam Longwall Mining. Energies 2019, 12, 1375. [CrossRef]

10. Fu, M.; Liu, S.; Su, F. An experimental study of the vibration of a drill rod during roof bolt installation. Int. J. Rock Mech. Min. Sci. 2018, 104, 20-26. [CrossRef]

11. Marta, D. Tunnel complex unloaded by a deep excavation Computers and Geotechnics. Comput. Geotech. 2001, 28, 469-493.

12. Meng, Q.; Han, L.; Xiao, Y.; Li, H.; Wen, S.; Zhang, J. Numerical simulation study of the failure evolution process and failure mode of surrounding rock in deep soft rock roadways. Int. J. Min. Sci. Technol. 2016, 26, 209-221. [CrossRef]

13. Kulatilake, P.H.S.W.; Wu, Q.; Yu, Z.; Jiang, F. Investigation of stability of a tunnel in a deep coal mine in China. Int. J. Min. Sci. Technol. 2013, 23, 579-589. [CrossRef]

14. Fan, X.; Li, K.; Lai, H.; Xie, Y.; Cao, R.; Zheng, J. Internal stress distribution and cracking around flaws and openings of rock block under uniaxial compression: A particle mechanics approach. Comput. Geotech. 2018, 102, 28-38. [CrossRef]

15. Jiang, L.; Sainoki, A.; Mitri, H.S.; Ma, N.; Liu, H.; Hao, Z. Influence of fracture-induced weakening on coal mine gateroad stability. Int. J. Rock Mech. Min. Sci. 2016, 88, 307-317. [CrossRef]

16. Andrea, L.; Daniel, F.; Giovanni, G. Fracture development around deep underground excavations Insights from FDEM modeling. J. Rock Mech. Geotech. Eng. 2014, 6, 493-505.

17. Yang, S.; Chen, M.; Jing, H.; Chen, K.F.; Meng, B. A case study on large deformation failure mechanism of deep soft rock roadway in Xin'an coal mine, China. Eng. Geol. 2017, 217, 89-101. [CrossRef]

18. Chang, J.; Xie, G. Mechanical characteristics and stability control of rock roadway surrounding rock in deep mine. J. China Coal Soc. 2009, 7, 881-886. 
19. Chang, J. Study on complex roof support technology of mining gateway in deep mine. Coal Sci. Technol. 2016, 60-63, 77.

20. Chang, J.; Xie, G. Research on Response Characteristics of Bolt Pretension on Supporting Effect of Rock Roadway in Coal Mine. J. Min. Safety Eng. 2012, 29, 657-661.

21. Gao, F.; Stead, D.; Kang, H. Numerical simulation of squeezing failure in a coal mine roadway due to mining induced stresses. Rock Mech. Rock Eng. 2015, 48, 1635-1645. [CrossRef]

22. Ma, X.; He, M.; Wang, J.; Gao, Y.; Zhu, D.; Liu, Y. Mine strata pressure characteristics and mechanisms in gob-side entry retention by roof cutting under medium-thick coal seam and compound roof conditions. Energies 2018, 11, 2539. [CrossRef]

23. Yuan, Y.; Wang, W.; Li, S. Failure mechanism for surrounding rock of deep circular roadway in coal mine based on mining-induced plastic zone. Adv. Civ. Eng. 2018, 2018, 1835381. [CrossRef]

24. Ma, N.; Zhao, X.; Zhao, Z.; Li, J.; Guo, X.F. Stability analysis and control technology of mine roadway roof in deep mining. J. China Coal Soc. 2015, 10, 2287-2295.

25. Zhao, Z.; Ma, N.; Guo, X.; Zhao, X.; Fan, L. Falling principle and support design of butterfly-failure roof in large deformation mining roadways. J. China Coal Soc. 2016, 41, 2932-2939.

26. Ma, N.; Li, J.; Zhao, Z. Distribution of the deviatoric stress field and plastic zone in circular roadway surrounding rock. J. China Univ. Min. Technol. 2015, 2, 206-213.

27. Manchao, H.; e Sousa, R. L.; Müller, A.; Vargas, E., Jr.; e Sousa, L. R.; Xin, C. Analysis of excessive deformations in tunnels for safety evaluation. Tunn. Undergr. Space Technol. 2015, 45, 190-202. [CrossRef]

28. Gao, Y.; Yang, J.; He, M.; Wang, Y.; Gao, Q. Mechanism and control techniques for gangue rib deformations in gob-side entry retaining formed by roof fracturing in thick coal seams. Chin. J. Rock Mech. Eng. 2017, 36, 2492-2502.

29. He, M.; Gao, Y.; Yang, J.; Guo, Z.; Wang, E.; Wang, Y. An energy-gathered roof cutting technique in no-pillar mining mining and its impact on stress variation in surrounding rocks. Chin. J. Rock Mech. Eng. 2017, 36, 1314-1325.

30. Gu, S.; Jiang, B.; Wang, G.; Dai, H.; Zhang, M. Occurrence mechanism of roof-fall accidents in large-section coal seam roadways and related support design for Bayangaole coal mine, China. Adv. Civ. Eng. 2018, 2018, 6831731. [CrossRef]

31. Gu, S.; Hu, C.; Dai, H.; Chao-chao, Y. Mechanical analysis of surrounding rock reinforced by prestressed bolt with subsection anchor. Rock Soil Mech. 2017, 38, 2826-2832.

32. Xie, J.; Xu, J.; Zhu, W. Gray lgebraic curve model-based roof separation prediction method for the warning of roof fall accidents. Arab. J. Geosci. 2016, 9, 514. [CrossRef] 